\title{
BORO E MAGNÉSIO NA PRODUÇÃO DE ÓLEO ESSENCIAL DE Corymbia citriodora E TEOR DE CLOROFILA
}

\author{
Érica Alexandrino Fávaro ${ }^{1}$, Antônio Carlos Tadeu Vitorino ${ }^{2}$, Omar Daniel $^{3}$, José Oscar Novelino² \\ ${ }^{1}$ Bióloga, M.Sc., Faculdade de Ciências Agrárias, UFGD, Dourados, MS, Brasil - erifava@ terra.com.br \\ ${ }^{2}$ Eng. Agrônomo, Dr., Faculdade de Ciências Agrárias, UFGD, Dourados, MS, Brasil - antoniovitorino@ufgd.edu.br; \\ josenovelino@ufgd.edu.br \\ ${ }^{3}$ Eng. Florestal, Dr., Faculdade de Ciências Agrárias, UFGD, Dourados, MS, Brasil - omar.daniel@pq.cnpq.br
}

Recebido para publicação: 13/02/2010 - Aceito para publicação: 12/05/2010

\begin{abstract}
Corymbia citriodora tem apresentado destacada importância na economia brasileira, por ser uma espécie pouco susceptível a variações edafoclimáticas, o que permite seu amplo cultivo nas diversas regiões do país, além de ser ótimo produtor de óleo essencial. O presente trabalho teve como objetivo estudar os efeitos dos nutrientes boro e magnésio na produção de óleo essencial de Corymbia citriodora e teor de clorofila. Dois experimentos foram realizados e analisados separadamente, sendo um utilizando Neossolo Quartzarênico (RQ) e outro com Latossolo Vermelho Distrófico (LVd), sendo as plantas cultivadas em vasos de $3,5 \mathrm{dm}^{3}$ de solo. Os experimentos foram montados em sistema fatorial 4 x 5 , quatro níveis de magnésio $\left(0,0 ; 0,3 ; 0,6\right.$ e $\left.0,9 \mathrm{cmol}_{\mathrm{c}} \cdot \mathrm{dm}^{-3} \mathrm{de} \mathrm{Mg}\right)$ e cinco níveis de boro $\left(0,00 ; 0,25 ; 0,50 ; 0,75\right.$ e $\left.1,00 \mathrm{mg}^{-\mathrm{dm}^{-3}} \mathrm{de} \mathrm{B}\right)$, dispostos no delineamento em blocos casualizados com quatro repetições. As mudas foram mantidas em casa de vegetação nos primeiros 15 dias e, sequencialmente, foram colocados em condições de luminosidade natural, onde ficaram por um período de seis meses. Os resultados obtidos permitiram concluir que os teores de $\mathrm{B}$ e $\mathrm{Mg}$ afetaram os teores de clorofila e o rendimento de óleo essencial em mudas de C. citriodora.

Palavras-chave: Corymbia citriodora; óleo de eucalipto; nutrientes.
\end{abstract}

\begin{abstract}
Boron and Magnesium on Corymbia citriodora production and chlorophyll content. The Corymbia citrodora has been presented highlighted importance in the Brazilian economy, for being a little susceptive species to the pedo-climatic variations, what allows its cultivation in many regions besides being an excellent essential oil producer. The objective was to study the effect of the nutrients boron and magnesium on the Corymbia citriodora oil production and chlorophyll content. Two experiments had been carried through and analyzed separately, being one using Typic Quartzipsamment soil (RQ) and Typic Dystrophic Red Latosol (Oxisol) (LVd), where the plants had been cultivated in vases of $3,5 \mathrm{dm}^{3}$. The experiments had been designed in factorial system $4 \times 5,\left(0,0 ; 0,3 ; 0,6\right.$ and $0,9 \mathrm{cmol}_{\mathrm{c}}$ $\mathrm{dm}^{-3}$ of $\left.\mathrm{Mg}\right)$ and $\left(0,00 ; 0,25 ; 0,50 ; 0,75\right.$ and $1,00 \mathrm{mg} \mathrm{dm}^{-3}$ of B), using the delineation block-type randomized with four repetitions. Seedlings were kept in a greenhouse in the first 15 days and sequentially placed in conditions of natural luminosity, where they had been for a period of 6 months. From the obtained results we can conclude that the contents of $\mathrm{B}$ and $\mathrm{Mg}$ had affected chlorophyll content and the essential oil production of $C$. citriodora seedlings.
\end{abstract}

Keywords: Corymbia citriodora; eucalyptus lemon oil; nutrients.

\section{INTRODUÇÃO}

A espécie Corymbia citriodora (Hook.) K.D. Hill \& L.A.S. Johnson tem apresentado destacada importância na economia do país, por ser uma espécie pouco susceptível às variações edafoclimáticas, o que permite seu amplo uso para cultivo nas diversas regiões do país, além de ser ótima produtora de óleo essencial (MATOS, 2006).

O interesse do homem pelos óleos essenciais está baseado na possibilidade de obtenção de compostos aromáticos, os quais, de uma forma ou de outra, fazem parte do nosso cotidiano. Os óleos essenciais provenientes dos gêneros Eucalyptus e Corymbia ocorrem principalmente nas folhas, onde são 
produzidos em pequenas glândulas, distribuídas em todo o parênquima foliar da maioria de suas espécies (VITTI; BRITO, 2003).

É de se esperar que plantas adequadamente nutridas e crescendo em ambientes favoráveis devam apresentar um bom desempenho na produção de óleo essencial, sendo de grande significado o entendimento da participação dos nutrientes nesse processo. Dessa forma, alguns macro e micronutrientes são de extrema importância para que o eucalipto tenha um bom desenvolvimento e produção de madeira. Nesse contexto, o boro, que atua no crescimento meristemático das plantas (SILVEIRA, 1996), destaca-se como sendo um dos nutrientes que mais limitam o crescimento e desenvolvimento do eucalipto. Estudos realizados por Goldbach et al. (2007) relatam que a deficiência de boro também pode afetar indiretamente o processo de fotossíntese.

Em se tratando da produção de óleos essenciais, são raros os trabalhos encontrados na literatura que relacionem os efeitos dos nutrientes sobre a produção de óleos (MAFFEIS et al., 2000). Quanto ao Eucalyptus, especificamente, relatos de Silveira (1996) e de Maffeis et al. (2000) indicam a redução na produção de citronelal em condições de deficiência de boro.

Além do boro, outro elemento que tende a se mostrar importante na produção de óleo essencial em eucaliptos é o magnésio. Num trabalho realizado por Maffeis et al. (2000), sobre deficiências de macronutrientes e boro na produção de óleo essencial, os autores perceberam que as plantas cultivadas na omissão do magnésio apresentaram maior produção, necessitando então de mais estudos sobre esse nutriente em relação à produção de óleo essencial em eucaliptos. Segundo Pereira (2001), a carência de resultados envolvendo a avaliação do crescimento de folhas em função de potássio e magnésio é um fato marcante na literatura.

Desse modo, o presente estudo teve como objetivo avaliar e quantificar os efeitos de doses de boro (B) e magnésio (Mg) na produção de óleo essencial de Corymbia citriodora e no teor de clorofila.

\section{MATERIAL E MÉTODOS}

O experimento foi realizado, no período de dezembro de 2006 a junho de 2007. Foram realizados dois experimentos em vasos, com capacidade para $3,5 \mathrm{dm}^{3}$ de solo, sendo cada vaso considerado como uma parcela experimental.

No experimento 1 foi utilizado um Neossolo Quartzarênico, sob vegetação natural de Cerrado, coletado no município de Jateí, MS.

No experimento 2 foi utilizado um Latossolo Vermelho Distrófico, textura média, coletado no município de Antônio João, MS. Subamostras desses materiais foram submetidas a análises químicas no Laboratório de Fertilidade de Solos da FCA/UFGD, utilizando a metodologia proposta por EMBRAPA (1997).

O delineamento experimental utilizado foi em blocos casualizados, com quatro repetições, seguindo o sistema fatorial 4 x 5 , utilizando-se quatro níveis de magnésio $\left(0,0 ; 0,3 ; 0,6\right.$ e $0,9 \mathrm{cmol}_{\mathrm{c}} \cdot \mathrm{dm}^{-3}$ de $\mathrm{Mg}$ ) e cinco níveis de boro $\left(0,00 ; 0,25 ; 0,50 ; 0,75\right.$ e $1,00 \mathrm{mg}^{-\mathrm{dm}^{-3}}$ de B), totalizando 80 parcelas em cada experimento (cada solo) e 170 parcelas no total.

Com exceção de B e Mg, que foram os tratamentos, cada vaso (parcela) recebeu uma adubação básica com macro e micronutrientes, seguindo orientação de Novais et al. (1991).

As doses de $\mathrm{B}$ e $\mathrm{Mg}$ foram adicionadas por meio de soluções (as fontes utilizadas foram $\mathrm{H}_{3} \mathrm{BO}_{3} \mathrm{e}$ $\mathrm{MgCl}_{2} \cdot 6 \mathrm{H}_{2} \mathrm{O}$ ). A semeadura foi feita utilizando-se aproximadamente 10 sementes de Corymbia citriodora, com desbastes 15 dias após a germinação.

Ao final de seis meses, foram coletadas as folhas de todos os vasos, no mesmo dia, entre 7 e 8 horas da manhã, identificadas e congeladas em freezer. Todas as extrações de óleo essencial foram feitas por hidrodestilação em aparelho Clevenger, com balões com capacidade para 2 litros, com a finalidade de separar a parte volátil do óleo essencial do restante não volátil que permanece nas partes da planta. As folhas eram retiradas do freezer à medida que seriam destiladas. Um mês antes da coleta das folhas para a extração e obtenção do óleo essencial, foram retiradas três folhas por planta para avaliação de teor de clorofila de $C$. citriodora em relação às doses de boro e magnésio, conforme metodologia recomendada por Arnon (1949). Clorofila Total: (20,2 x A $645+8,02$ x A 663). Os resultados de clorofila total foram dados em $\mu \mathrm{g} / \mathrm{g}$ de peso fresco, e os de rendimento de óleo essencial em g $100 \mathrm{~g}^{-1}$ de peso fresco (\%). Para os cálculos de rendimento considerou-se a densidade de 0,85 g.cm ${ }^{-3}$, segundo parâmetros ISO 3044-1974 revisados em 1997. Os dados foram analisados por regressão. 


\section{RESULTADOS E DISCUSSÃO}

\section{Análises dos dados para o solo 1 (Neossolo Quartzarênico)}

Teor de clorofila em função de doses de magnésio e boro

O teor máximo de clorofila foi observado quando se utilizou a dose $0,59 \mathrm{cmol}_{\mathrm{c}} \cdot \mathrm{dm}^{-3} \mathrm{de}$ magnésio, sendo de 115,82 $\mu \mathrm{g} \cdot \mathrm{g}^{-1}$ (Figura 1). O teor de clorofila aumentou até a dose de $0,50 \mathrm{mg} \cdot \mathrm{dm}^{-3} \mathrm{de}$ boro, proporcionando um teor máximo de clorofila de 109,14 $\mu \mathrm{g} \cdot \mathrm{g}^{-1}$ (Figura 2), havendo após um declínio com doses crescentes.

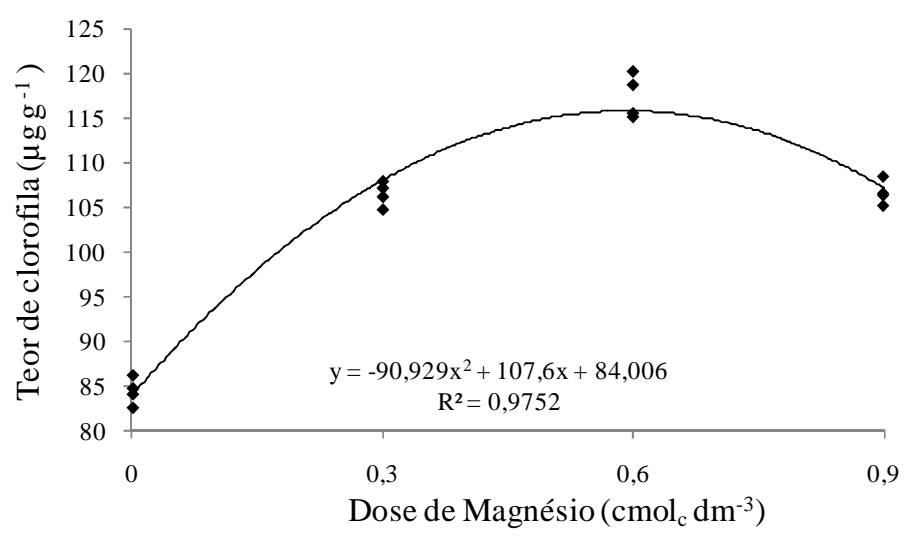

Figura 1. Teor médio de clorofila de folhas de Corymbia citriodora em função de doses de magnésio adicionadas ao solo 1 (Neossolo Quartzarênico).

Figure 1. Average content of chlorophyll of Corymbia citriodora leaves as function of magnesium doses added to the soil 1 (Typic Quartzipsamment).

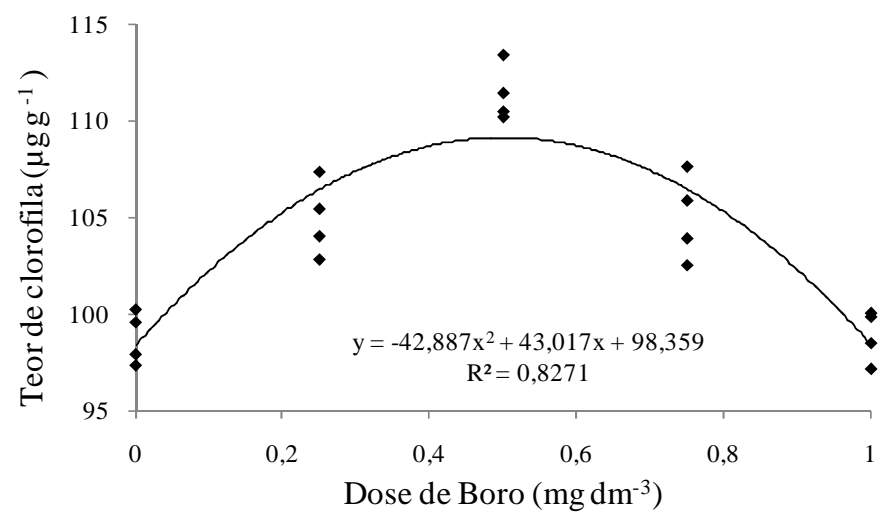

Figura 2. Teor médio de clorofila de folhas de Corymbia citriodora em função de doses de boro adicionadas ao solo 1 (Neossolo Quartzarênico).

Figure 2. Average content of chlorophyll of Corymbia citriodora leaves as function of boron doses added to the soil 1 (Typic Quartzipsamment ).

Silveira (1996), ao analisar folhas de E. citriodora deficientes em macronutrientes e boro, observou que as deficiências de boro foram as que mais reduziram o número de glândulas produtoras de óleo essencial por $\mathrm{cm}^{2}$ de limbo foliar quando comparadas às folhas com tratamento completo. A redução na quantidade de glândulas na carência de boro e nitrogênio foram de 5 e 2,5 vezes, respectivamente, em relação ao tratamento completo. 
Segundo Moraes et al. (2002), na deficiência de boro ocorre redução da síntese de pectina e lignina, tornando mais finas as paredes das células do lenho, o que acarreta menor crescimento e menor produção de folhas das plantas.

Rendimentos de óleo essencial em função de doses de magnésio e boro

$\mathrm{O}$ melhor rendimento de óleo essencial foi atingido com a dose de $0,71 \mathrm{cmol}_{\mathrm{c}} \cdot \mathrm{dm}^{-3} \mathrm{de} \mathrm{Mg}$, proporcionando o maior rendimento, de $1,16 \%$ (Figura 3), enquanto o máximo rendimento de óleo essencial foi de $1,00 \%$ na dose $0,56 \mathrm{mg} \cdot \mathrm{dm}^{-3}$ de boro (Figura 4 ).

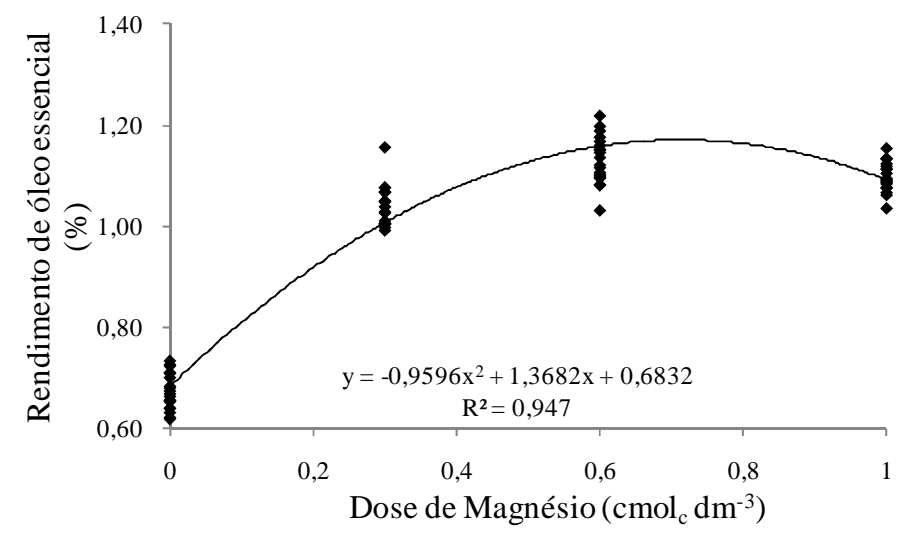

Figura 3. Teor médio de rendimento de óleo essencial de folhas de Corymbia citriodora em função de doses de magnésio adicionadas ao solo 1 (Neossolo Quartzarênico).

Figure 3. Average content of essential oil of Corymbia citriodora leaves yield as function of doses of magnesium added to the soil 1 (Typic Quartzipsamment).

Na ausência de magnésio, o rendimento de óleo essencial foi de $0,68 \%$, havendo um acréscimo de $71 \%$ no rendimento de óleo, até que se obtivesse a máxima eficiência técnica (MET), evidenciando mais ainda o efeito benéfico desse elemento ou de uma planta adequadamente nutrida com referência à produção de óleo essencial.

A quantidade de óleo essencial produzida está fortemente relacionada com as condições adequadas de crescimento e desenvolvimento da planta e, consequentemente, com a produção de folhas. As menores quantidades de óleo essencial por planta foram observadas por Moura et al. (1998) na omissão de boro, fato esse devido a uma drástica redução na produção de folhas.

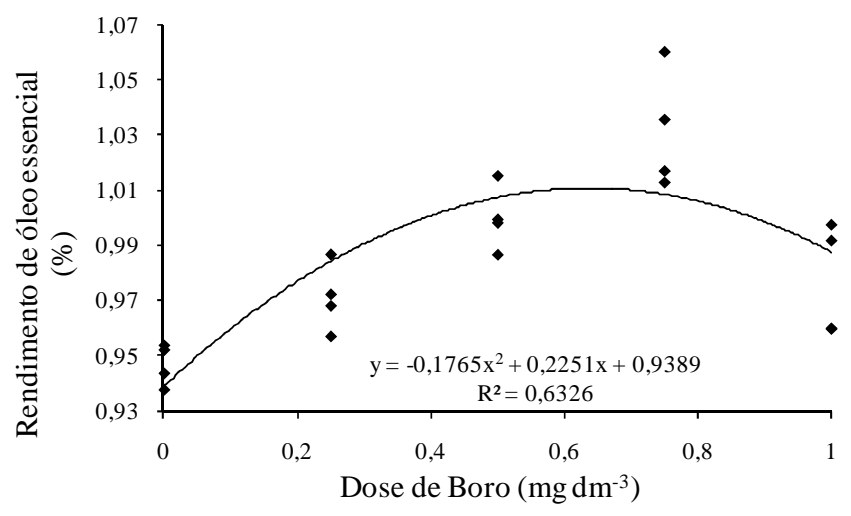

Figura 4. Teor médio de rendimento de óleo essencial de folhas de Corymbia citriodora em função de doses de boro adicionadas ao solo 1 (Neossolo Quartzarênico).

Figure 4. Average content of essential oil of Corymbia citriodora leaves yield as function of doses of boron added to the soil 1 (Typic Quartzipsamment). 
Os nutrientes minerais são fundamentais para o crescimento da planta e, consequentemente, para uma boa produção de óleo essencial (GARLET et al., 2007). O estresse nutricional decorrente da deficiência ou do excesso de determinado nutriente interfere no metabolismo vegetal, sendo importante fator na redução da produtividade da planta e da quantidade e qualidade de óleo essencial (COSTA et al., 2007).

\section{Análises dos dados para o solo 2 (Latossolo Vermelho Distrófico)}

Teor de clorofila em função de doses de magnésio e boro

O máximo teor de clorofila foi obtido quando se utilizou a dose de $0,50 \mathrm{cmol}_{\mathrm{c}} \cdot \mathrm{dm}^{-3} \mathrm{de} \mathrm{Mg}$, sendo de 215,66 $\mu \mathrm{g} \cdot \mathrm{g}^{-1}$ (Figura 5).

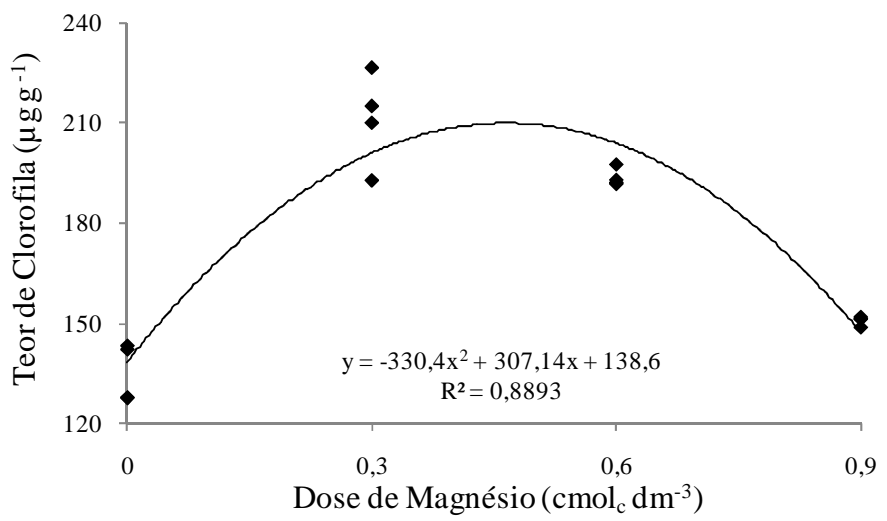

Figura 5. Teor médio de clorofila de folhas de Corymbia citriodora em função de doses de magnésio adicionadas ao solo 2 (Latossolo Vermelho Distrófico).

Figure 5. Average content of chlorophyll of Corymbia citriodora leaves as function of magnesium doses added to the soil 2 (Typic Dystrophic Red Latosol).

Uma planta com alto teor de clorofila é capaz de apresentar taxas fotossintéticas mais altas, pelo seu potencial de captação de "quanta" na unidade de tempo (PORRA et al., 1989; CHAPPELLE; KIM, 1992).

Para o boro, a dose de máxima eficiência técnica (MET) foi de $0,60 \mathrm{mg} \cdot \mathrm{dm}^{-3}$, que promoveu um teor de clorofila de 177,88 $\mu \mathrm{g} . \mathrm{g}^{-1}$ (Figura 6).

Goldbach et al. (2007) argumentaram que a função do boro no processo fotossintético ainda é desconhecida, mas a deficiência pode afetar o funcionamento das membranas do cloroplasto, afetando o transporte de elétrons no tilacoíde e resultando em fotoinibição. Entretanto a deficiência de boro pode ainda afetar indiretamente a fotossíntese e a transpiração, por meio da diminuição da área foliar e pela alteração dos compostos presentes na folha.

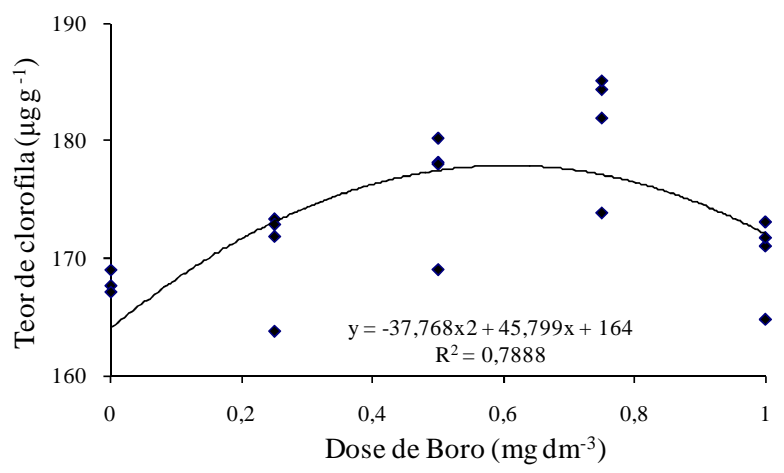

Figura 6. Teor médio de clorofila de folhas de Corymbia citriodora em função de doses de boro adicionadas ao solo 2 (Latossolo Vermelho Distrófico).

Figure 6. Average content of chlorophyll of Corymbia citriodora leaves as function of boron doses added to the soil 2 (Typic Dystrophic Red Latosol). 
Como houve interação significativa dos fatores boro e magnésio para os teores de clorofila, fezse o desdobramento da interação. Observando-se os resultados de teores de clorofila (Tabela 1), é possível verificar que os maiores teores geralmente foram obtidos com a dose $0,30 \mathrm{cmol}_{c} \cdot \mathrm{dm}^{-3} \mathrm{de}$ magnésio. Esse efeito se deu independentemente dos teores de boro. Quando a dose de boro foi de 0,25 e $1 \mathrm{mg}^{-\mathrm{dm}^{-3}}$, não foram verificadas diferenças para doses de magnésio. Observa-se ainda que os maiores teores de clorofila foram conseguidos com a dose de $0,75 \mathrm{mg} \cdot \mathrm{dm}^{-3}$ de boro e, nesse caso, a dose de $0,90 \mathrm{cmol}_{\mathrm{c}} \cdot \mathrm{dm}^{-3} \mathrm{de}$ magnésio não diferiu da dose de $0,30 \mathrm{cmol}_{c} \cdot \mathrm{dm}^{-3}$.

Tabela 1. Teores médios de clorofila $\left(\mu \mathrm{g} \cdot \mathrm{g}^{-1}\right)$ em função das doses de boro, dentro de cada dose de magnésio.

Table 1. Average contents of clorofila $\left(\mu \mathrm{g} \cdot \mathrm{g}^{-1}\right)$ as function of the boron doses, inside of each dose of magnesium.

\begin{tabular}{lcccc}
\hline $\begin{array}{l}\text { Dose de boro } \\
\text { (mg.dm }\end{array}$ & \multicolumn{4}{c}{ Dose de magnésio $\left(\mathbf{c m o l}_{\mathbf{c}} \mathbf{.} \cdot \mathbf{d m}^{-3}\right)$} \\
\cline { 2 - 5 } & $\mathbf{0}$ & $\mathbf{0 , 3}$ & $\mathbf{0 , 6}$ & $\mathbf{0 , 9}$ \\
\hline 0 & $91.04 \mathrm{C}$ & $214.00 \mathrm{~A}$ & $141.80 \mathrm{BC}$ & $157.72 \mathrm{BC}$ \\
0,25 & $145.42 \mathrm{~A}$ & $168.44 \mathrm{~A}$ & $127.62 \mathrm{~A}$ & $123.24 \mathrm{~A}$ \\
0,5 & $141.58 \mathrm{C}$ & $275.02 \mathrm{~A}$ & $149.02 \mathrm{C}$ & $217.66 \mathrm{~B}$ \\
0,75 & $181.76 \mathrm{~B}$ & $289.34 \mathrm{~A}$ & $111.32 \mathrm{C}$ & $309.68 \mathrm{~A}$ \\
1 & $152.10 \mathrm{~A}$ & $201.96 \mathrm{~A}$ & $179.28 \mathrm{~A}$ & $165.20 \mathrm{~A}$ \\
\hline
\end{tabular}

Médias seguidas de mesma letra, na linha, não diferem entre si pelo teste de Tukey a $5 \%$.

Rendimento de óleo essencial em função de doses de magnésio e boro

A dose de $0,57 \mathrm{cmol}_{\mathrm{c}} \cdot \mathrm{dm}^{-3}$ de $\mathrm{Mg}$ proporcionou o rendimento de óleo essencial de $1,17 \%$, conforme figura 7, onde se pode observar que na ausência de $\mathrm{Mg}$ o rendimento de óleo essencial foi de $0,68 \%$, após calculada a MET. Percebe-se um aumento de $72 \%$ no rendimento de óleo essencial na presença do $\mathrm{Mg}$. Na ausência de boro, o rendimento de óleo essencial foi de $0,96 \%$, havendo um incremento de $5 \%$ no rendimento de óleo com a dose de $0,75 \mathrm{mg} \cdot \mathrm{dm}^{-3}$ de boro, obtendo-se $1,01 \%$ de produção de óleo essencial (Figura 8).

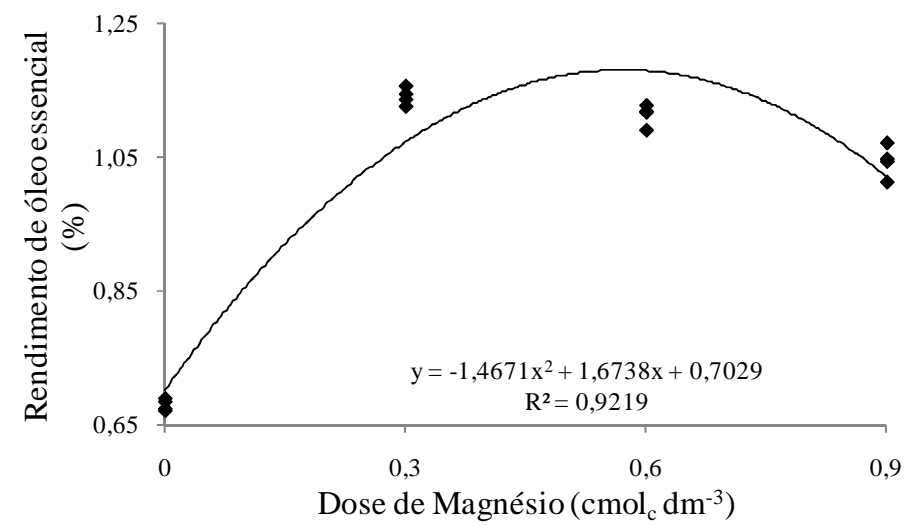

Figura 7. Teor médio de rendimento de óleo essencial de folhas de Corymbia citriodora em função de doses de magnésio adicionadas ao solo 2 (Latossolo Vermelho Distrófico).

Figure 7. Average content of essential oil of Corymbia citriodora leaves yield as function of doses of magnesium added to the soil 2 (Typic Dystrophic Red Latosol).

As relações de nutrientes disponíveis para a planta são importantes tanto para o desenvolvimento vegetativo da planta quanto para a qualidade do óleo essencial. Ainda segundo Maia (1998), as proporções do componente principal do óleo essencial são alteradas pelas condições de nutrição da planta. De acordo com Furtini et al. (2000), com relação à nutrição de espécies florestais, a demanda de alguns nutrientes é mais intensa na fase inicial de crescimento das plantas. Oliveira; Buzetti (1997) recomendam a aplicação de micronutrientes, principalmente B, em plantios de eucalipto, além da adubação com NPK. 


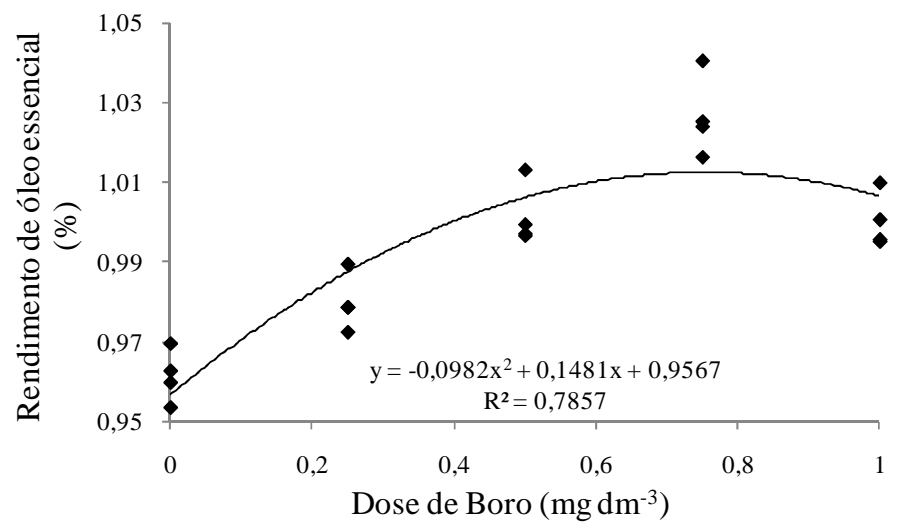

Figura 8. Teor médio de rendimento de óleo de folhas de Corymbia citriodora em função de doses de boro adicionadas ao solo 2 (Latossolo Vermelho Distrófico).

Figure 8. Average content of essential oil of Corymbia citriodoraleaves yield as function of doses of boron added to the soil 2 (Typic Dystrophic Red Latosol).

\section{CONCLUSÕES}

- Dos resultados obtidos, pode-se concluir que tanto o boro quanto o magnésio afetam os teores de clorofila e rendimento de óleo essencial em mudas de Corymbia citriodora em ambos os solos estudados.

- Em relação ao rendimento de óleo essencial em mudas de Corymbia citriodora, este também é afetado pelos teores de nutrientes de boro e magnésio no solo.

- As doses de magnésio e boro que resultaram em maior rendimento de óleo essencial foram, respectivamente, de $0,57 \mathrm{cmol}_{\mathrm{c}} \cdot \mathrm{dm}^{-3}$ e de $0,75 \mathrm{mg} \cdot \mathrm{dm}^{-3}$.

- Doses de boro acima de $0,75 \mathrm{mg} \cdot \mathrm{dm}^{-3}$ e de magnésio maiores do que $0,57 \mathrm{cmol}_{\mathrm{c}} \cdot \mathrm{dm}^{-3}$ causaram redução do teor de clorofila nas mudas.

- Doses de magnésio maiores do que $0,57 \mathrm{cmol}_{\mathrm{c}} \cdot \mathrm{dm}^{-3}$ causaram redução nos teores de óleo essencial nas mudas.

\section{REFERÊNCIAS}

ARNON, D. I. Copper enzymes in isolated chloroplasts: polyphenoloxydase in Beta vulgaris. Plant Fisiology, v. 24, n. 1, p. 1-15, 1949.

CHAPPELLE, E. W.; KIM, M. S. Ratio analysis of reflectance spectra (RARS): an algorithm for a remote estimation of the concentrations of clorophyll A, chorophyll B, and carotenoids in soybean leaves. Remote Sensing of Environment, New York, v. 39, p. 239-247, 1992.

COSTA, C. A.; ALVES, D. S.; FERNANDES, L. A.; MARTINS, E. R.; SOUZA, I. G. B.; SAMPAIO, R. A.; LOPES, P. S. N. Nutrição mineral da fava d'anta. Horticultura Brasileira, Brasília, DF, v. 25, n. 1, p. 24-28, 2007.

EMBRAPA. Centro Nacional de Pesquisa de Solos. Sistema brasileiro de classificação de solos. 2. ed. Rio de Janeiro, 1997. 212 p. (EMBRAPA-CNPS. Documentos, 1).

FURTINI, A. E. Fertilização em reflorestamento com espécies nativas. In: GONÇALVES, J. L. Nutrição e fertilização florestal. Piracicaba: IPEF, 2000. p. 351-383.

GARLET, T. M. B.; SANTOS, O. S.; APEL, M. A.; FLORES, R. Teor e qualidade do óleo essencial de Mentha $\mathrm{x}$ gracilis Sole (Lamiaceae) cultivada em hidroponia. Revista Brasileira de Biociências, Porto Alegre, v. 5, supl. 2, p. 114-116, 2007. 
GOLDBACH, H. E.; HUANG, L.; WIMMER, M. A. Boron functions in plants and animals: recent advances in boron research and open questions. In: INTERNATIONAL SYMPOSIUM ON ALL ASPECTS OF PLANT AND ANIMAL BORON NUTRITION, 3, 2007, Wuhan. Proceedings...Wuhan, Springer, 2007. p. 3-25.

MAFFEIS, A. R.; SILVEIRA, R. L. V. A.; BRITO, J. O. Reflexos das deficiências de macronutrientes e boro no crescimento de plantas, produção e qualidade de óleo essencial em Corymbia citriodora. Scientia Forestalis, Piracicaba, SP, n. 57, p. 87-98, 2000.

MAIA, N. B. Produção e qualidade do óleo essencial de duas espécies de menta cultivadas em soluções nutritivas. Piracicaba. 1998. 105 f. Tese (Doutorado em Agronomia) - Escola Superior de Agricultura "Luiz de Queiroz", Universidade de São Paulo.

MATOS, E. Centro de Apoio ao Desenvolvimento tecnológico - CDT/UnB. Campus UnB - Faculdade de Tecnologia. Brasília, Módulo AT-5, 2006.

MORAES, L. A. C.; MORAES, V. H. F.; MOREIRA, A. Relação entre flexibilidade do caule de seringueira e a carência de boro. Pesquisa Agropecuária Brasileira, Brasília, v. 37, p. 1431-1436, 2002.

MOURA, L. F.; SGARBI, F.; MAFFEIS, A. R.; SILVEIRA, R. L. V. A.; BRITO, J. O.; KITAJIMA, E. W. Análise de elementos anatômicos em folhas de Corymbia citriodora, cultivada sob condições de omissão de macronutrientes e boro através da MEV. In: SIMPÓSIO DE INICIAÇÃO CIENTÍFICA DA UNIVERSIDADE DE SÃO PAULO, 6; REUNIÃO PAULISTA DE INICIAÇÃO CIENTÍFICA EM CIÊNCIAS AGRÁRIAS, 9; CONGRESSO DE INICIAÇÃO CIENTÍFICA DA ESALQ, 12, Piracicaba, 1998. Resumos... Piracicaba, ESALQ, 1998. v. 1, p. 498.

NOVAIS, R. F.; NEVES, J. C. L.; BARROS, N. F. Ensaio em ambiente controlado. In: OLIVEIRA, A. J.; GARRIDO, W. E.; ARAÚJO, J. D.; LOURENÇO, S. Método de pesquisa em fertilidade do solo. Brasília: Embrapa-SEA, 1991. p. 189-253.

OLIVEIRA, S. A.; BUZETTI, S. Efeito da aplicação de NPK e micronutrientes no desenvolvimento de Corymbia citriodora Hook. Floresta, Curitiba, PR, v. 29, p. 27-36, 1997.

PEREIRA, W. L. M. Doses de potássio e de magnésio em solução nutritiva para capim-mombaça. Piracicaba, 2001. 124 f. Tese (Doutorado) - Escola Superior de Agricultura "Luiz de Queiroz", Universidade de São Paulo.

PORRA, R. J.; THOMPSON, W. A.; KRIDEMANN, P. E. Determination of accurate extinction coefficients and simultaneous equations for assaying a and $\mathrm{b}$ extracted with four different solvents: verification of the concentration of chorophylls standards by atomic absorption spectroscopy. Biochimic et Biophysica Acta, Amsterdam, v. 975, p. 384-394, 1989.

SILVEIRA, R. L. V. A. Crescimento e estado nutricional de Corymbia citriodora sob doses de boro e sua relação com a agressividade de Brotrysphaeria ribis. 1996. 100 f. Dissertação (Mestrado em Solos e Nutrição de Plantas) - Escola Superior de Agricultura "Luiz de Queiroz", Piracicaba, 1996.

VITTI, A. M. S.; BRITO, J. O. Óleo essencial de eucalipto. Piracicaba: ESALQ. 2003. 30 p. (Documentos Florestais, 17). 